\title{
Acid suppressive agents and risk of Mycobacterium Tuberculosis: case-control study
}

\author{
Wen-Hung Hsu, ${ }^{1,}{ }^{\dagger}$, Chao-Hung Kuo ${ }^{1,2}$, Sophie SW Wang ${ }^{1}$, Chien-Yu Lu ${ }^{1,2}$, Chung-Jung Liu ${ }^{1 \dagger}$, Seng-Kee Chuah ${ }^{3}$, \\ Fu-Chen $\mathrm{Kuo}^{4}$, Yen-Hsu Chen ${ }^{5}$, Yaw-Bin Huang ${ }^{6}$, Ming-Feng Hou', Deng-Chyang Wu ${ }^{1,2,8}$ and Huang-Ming Hu ${ }^{1,2^{*}}$
}

\begin{abstract}
Background: The acid-suppressive agents have been linked with an increased risk of infectious disease. The relationship between these drugs and Mycobacterium Tuberculosis (TB) was not been reported.

Methods: We conducted a case-control study using data from National Health Insurance research database of Taiwan. From 1996 till 2008, and 6541 cases were defined as TB infection/activation (ICD-9 coding plus prescription two of four first-line anti-TB regimen for at least one month). Control subjects who were matched to the TB cases by age and sex were selected with 10:1 ratio. Medical records including acid-suppressive agent prescription and comorbidity, and socioeconomic status were analyzed.

Results: TB infection/activation was more frequent to comorbidity with chronic diseases, alcohol abuse, malignancy, immune deficient/suppression status and acid-related disease (peptic ulcer, reflux esophagitis). Among the TB cases, there was higher exposure record to acid-suppressive agents within 3 months before TB index date (OR 2.43(2.06-2.88) and 1.90 (1.68-2.14) for proton pump inhibitor (PPI) and histamine 2 receptor antagonist $\left(\mathrm{H}_{2} \mathrm{RA}\right.$ ) respectively). After adjusting confounding factors, PPIs prescription 3 months before TB index date had an association of TB infection/activation (adjusted OR 1.63(1.61-1.63)). Similar result was found in $\mathrm{H}_{2} \mathrm{RA}$ user (adjusted OR 1.51(1.50-1.52)). The association of acid-suppressive agents in TB infection/activation was fade gradually when the drug prescription period extended.
\end{abstract}

Conclusions: Recent prescription of acid-suppressive agent seems to associate the TB infection/activation. In the society where TB was prevalent, evaluation of pulmonary TB before prescription of PPI or $\mathrm{H}_{2} \mathrm{RA}$ is warranted.

Keyword: Proton pump inhibitor, Histamine2-receptor antagonist, Mycobacterium Tuberculosis, National health insurance database, Taiwan

\section{Background}

Gastric acid plays an important role in decontamination of upper gastrointestinal tract. Following the widespread use of acid-suppressive agents [1-3], which are the mainstream of treatment in peptic ulcer disease and acid reflux associated esophageal disease, its eliminating acid barrier effect had been implied the association with infectious disease. Proton pump inhibitor (PPI) had marketed for more than two decades, and several studies had mentioned its

\footnotetext{
* Correspondence: kevinhu837@gmail.com

${ }^{\dagger}$ Equal contributors

'Division of Gastroenterology, Department of Internal Medicine, Kaohsiung Medical University Hospital, Kaohsiung City 807, Taiwan

${ }^{2}$ Department of Medicine, Faculty of Medicine, College of Medicine,

Kaohsiung Medical University, Kaohsiung City 807, Taiwan

Full list of author information is available at the end of the article
}

direct link to several enteric infections, such as Clostridium diffcile colitis, Salmonella enteritis [4,5] and spontaneous bacterial peritonitis in patients with advanced cirrhosis [6]. In addition, some population- or hospital- based studies of respiratory tract infection also revealed the increased risk of nosocomial and community-acquired pneumonia in patients with PPI use, while the role of histamine 2 receptor antagonist $\left(\mathrm{H}_{2} \mathrm{RA}\right)$ was controversial [7-9]. Among variant respiratory tract infectious disease, Mycobacterium tuberculosis (TB) infection is still an important health problem in many developing countries. With the characteristics of latent and indolent phases and the emergence of drug resistance [10], the resurgence of TB has great impact on public health [11].

\section{Ciomed Central}

(C) 2014 Hsu et al.; licensee BioMed Central Ltd. This is an Open Access article distributed under the terms of the Creative Commons Attribution License (http://creativecommons.org/licenses/by/2.0), which permits unrestricted use, distribution, and reproduction in any medium, provided the original work is properly credited. 
Unlike in developing countries, the disease used to be uncommon in developed countries, but it has re-emerged in the Western countries as a result of the acquired immunodeficiency syndrome (AIDS) epidemic therein as well as the influx of immigrants from developing countries $[12,13]$.

Previous reports have shown a high prevalence of tuberculosis among patients who have undergone gastrectomy, and gastrectomy is considered to be a risk factor for the development of tuberculosis. [14,15] But, the role of gastric acid in TB infection was still unknown.

To our best knowledge, there was no large study which examined the association between acid-suppressive agents and TB. Here, we utilized the database from Taiwan National Health Insurance (NHI) to evaluate its correlation under a population-based, case-control analysis.

\section{Methods}

\section{Study population and source of data}

The NHI program was implemented in Taiwan since 1995, and it offered a comprehensive, unified, and universal health insurance program to all citizens. The state-run Bureau of National Health Insurance (BNHI) contracted with $97 \%$ of hospitals as well as $90 \%$ of clinics. The BNHI collected all the administrative and claim data between March 1995 and December 2009, these data were anonymous.

The data was analyzed from the National Health Insurance Research Dataset (NHIRD), published by the National Health Research Institute (NHI) in Taiwan.

Taiwan's National Health Insurance program insures approximately 23 million people, $99 \%$ of its population. It offers complete freedom of choice among healthcare providers contracted with the NHI and comprehensive benefits including inpatient care, ambulatory care, dental care, and prescription drugs. The NHI resources, including physician visits, hospital care, and prescribed medications. Using this database, we can identify cohorts, track medical history, establish a prescription drug profile, and set endpoints when researching outcomes. Therefore, the NHIRD is one of the largest and most complete nationwide population-based datasets in Taiwan and there were no statistically significant differences in age, sex, and average insured payroll-related amount between the sample group and all enrollees.

This study used the 1996-2008 National Health Insurance Research Database (NHIRD) that is derived from NHI program which provided a database of 1,000,000 random subjects for research purposes.

Because these were secondary data, each patient's original identification number has been encrypted to protect privacy by a consistent procedure, so that the linkage of claims belonging to the same patient is feasible within the NHI Research Database.

\section{Definition of TB infection/activation}

We defined active TB from NHRID by compatible ICD9-CM (International Classification of Disease, $9^{\text {th }}$ Revision, Clinical Modification) codes of TB (010-108) plus the prescription of two of four first-line anti-tuberculosis medications (rifampin, isoniazid, pyrazinamide, ethambutol) for more than 28 days.

All patients who had match TB inclusion criteria were included. Under this definition, both of new symptomatic infection and reactivation who need treatment were included. Theoretically, It also included pulmonary, extra-pulmonary, child and adult. Ultimately, 6,541 patients with TB were included in the study group. Their first ambulatory care visits was assigned as index ambulatory care visits.

\section{Control group}

Matched controls group for this study was likewise extracted from the Registry of Beneficiaries of the NHIRD. We randomly selected 65,410 control subjects (10 for every TB patient), matched with the study group in terms of age, sex and the year and month of index visit.

\section{Comorbidity}

Several underline diseases had been shown to increase the risk of TB infection/activation [16,17], we collected those ICD-9 coding as confounding variables. Furthermore, gastric acid-related gastrointestinal diseases which act as a predictor of using acid-suppressive medication were also included for comorbidity analysis (Table 1). The definition of cormobidity was defined when those ICD-9 coding existed within 3 months before the diagnostic date of TB infection/activation.

\section{Table 1 ICD-9-CM codes used for Comorbidity}

\begin{tabular}{ll}
\hline Congestive heart failure & $\mathbf{4 2 8}$ \\
\hline Coronary heart disease & $410-41405$ \\
Chronic pulmonary disease & $493,494,501-5089$ \\
Diabetes Mellitus & $2500-2509$ \\
End stage renal disease & 585 \\
Liver cirrhosis & $5712,5715,5716$ \\
Alcohol abuse & $291,292,303,304,305$ \\
Peptic ulcer disease & $531,532,533,534$ \\
Reflux esophagitis & 53011,53081 \\
Gastrectomy & 534 \\
HIV & 042 \\
Connective tissue disease & $710,714,446,4476,1361$, \\
Malignant neoplasm & $7112,7111,6944,556,340,3580$ \\
Organ transplantation & $140-208$ \\
\hline
\end{tabular}




\section{Exposure of acid-suppressive agents}

Acid-suppressive agents included PPI (omeprazole, pantoprazole, lanosoprazole, rabeprazole, esomeprazole) and $\mathrm{H}_{2} \mathrm{RA}$ (cimetidine, ranitidine, famotidine) which were marketed in Taiwan during the observing period. The exposure of acid- suppressive agents was considered when the average dosage was more than half of the defined daily dose (DDD) during the observing period. The defined daily dose (DDD) recommended by the WHO is a unit for measuring a prescribed amount of drug; it is the assumed average maintenance dose per day of a drug consumed for its main indication in adults. We estimated dose-response relationship by using the cumulative amount of PPIs redeemed during the past 90 days, past 180 days, past 1 year and past 2 year as four periods. Cut-off points were greater than $50 \%$ DDD and non-use.

\section{Statistical analysis}

Chi-square test was used to compare the distribution of sociodemographic characteristics between patients with and patients without TB. We characterized comorbidity (Table 1) 1 year before index date. The crude and adjusted ORs with 95\% confidence intervals (CIs) of exposure for TB cases compared with control subjects were estimated using logistical regression. Previous diagnosis of comorbidity were either risk factors in univariate analyses of tuberculosis or were found to modify the OR for the association between acid suppressive agent and TB by at least $5 \%$ if included in a multivariate model. All these priori confounding factor were included in the multivariate analysis. Multivariate analysis was utilized to adjust variable confounding factors in order to identify the association between acid-suppressive agents and TB infection/activation. All the data processing and statistical analysis were performed with SAS 9.3 software.

\section{Results}

Between 1996 and 2008, there were 6541 patients who met the criteria of TB infection/activation. The characteristics of TB cases and controls were presented in Table 2. A $\mathrm{p}$ value $<0.05$ was considered statistically significant. Similar with previous studies, TB infection/activation was more frequent to comorbid with chronic diseases, alcohol abuse, malignancy and immune deficient/suppression status. Interestingly, TB cases also had higher prevalence of both peptic ulcer disease $(16.90 \%$ vs. $10.43 \%$ of controls, OR $1.75,95 \%$ CI 1.63-1.87) and reflux esophagitis (1.57\% vs. $1.02 \%$ of controls, OR $1.56,95 \%$ CI $1.27-1.92$ ) within three months before the TB diagnosis. As for the use of acid-suppressive agents, 173 out of 6541 TB cases (2.64\%) and 723 out of 65410 controls (1.11\%) were exposed to PPI medication within 3 months of diagnosis. During the same period, the use of $\mathrm{H}_{2} \mathrm{RA}$ in TB cases and controls were $5.16 \%$ and $2.79 \%$, respectively. After adjusting the confounding variables, their adjusted odds ratio (aOR) of using PPI or $\mathrm{H}_{2} \mathrm{RA}$ in TB cases were1.63 (95\% CI 1.611.63) (Table 3) and 1.51 (95\% CI, 1.50-1.52) (Table 4), respectively.

In order to clarify the association of long-term use of acid-suppressive agents and TB infection/activation, we also observed the prevalence of PPI or $\mathrm{H}_{2}$ RA use by definition of DDD higher than 50\% within 6,12 and 24 months before TB diagnosis (Tables 3 and 4). The higher possibility of PPI use in TB cases was still noted in 6 months in comparison to controls (aOR, 1.29, 95\%CI 1.29-1.30). However, the positive association disappeared in 12 and 24 months observing timeframe (Table 3 ). Similarly, the decreasing trend of association between $\mathrm{H}_{2} \mathrm{RA}$ and TB following the extension of observing timeframe was also found (Table 4). As the result, the influence of acidsuppressive agents in TB infection/activation was fade gradually when the drug prescription period extended (Figure 1).

\section{Discussion}

Acidic environment of stomach usually keep free from bacteria (except for Helicobacter pylori). Somehow, when stomach becomes less acidic, it loses this protective mechanism, and ingested organisms can survive and proliferate.[18]. It also can be the possible reason for the acid-suppressive agent with pneumonia. In Laheij et al. study, which 5,551 cases of community-acquired pneumonia developed in 364,683 people, found that the incidence of pneumonia was about 4.5 times higher in people exposed to acid-suppressive drugs (both PPIs and $\mathrm{H}_{2}$ RA) than in unexposed individuals.[7]. Subsequent had the similar results discussing the association of PPI with community-acquired pneumonia. [9,19-23]. Patients who developed community acquired pneumonia had higher odds of significant comorbidity conditions, including heart failure and chronic obstructive pulmonary disease. This possible association came to the attention of the general medical community. Although, the risk factors of pneumonia were complicated, the most important risk factor of pneumonia were aging, immunocompromised status and comorbility, $[24,25]$ which may overcome the importance of acid-suppressive agent.

Mycobacterium tuberculosis infection can present as an acute process and should be included in the differential diagnosis of community-acquired pneumonia. It is infected by Mycobacterium tuberculosis and may mimic classic bacterial pneumonia or masquerade as an atypical pneumonia, with nonproductive cough. Epidemiologic clues Mycobacterium tuberculosis share similar risk factor with community acquired pneumonia such as Diabetes mellitus, alcohol consumption, aging and HIV infection. In addition, intravenous drug abuse, immigration from countries of high prevalence, contact with Mycobacterium 
Table 2 Characteristics of cases with TB infection/activation and control subjects

\begin{tabular}{|c|c|c|c|}
\hline Characteristics & Case $\mathrm{n}=6541(\%)$ & Control $n=65410(\%)$ & OR $(95 \% \mathrm{Cl})$ \\
\hline Age $($ mean $\pm S D)$ & $57.78( \pm 19.55)$ & & \\
\hline Sex Male/Female & $4277 / 2264$ & $42770 / 22640$ & 1.0000 \\
\hline \multicolumn{4}{|l|}{ Income category } \\
\hline Monthly income $\leqq$ NT\$20000 & $5371(82.11)$ & $52016(79.52)$ & $0.79-0.90$ \\
\hline Monthly income > NT\$20000 & 1170(17.89) & 13394(20.48) & \\
\hline \multicolumn{4}{|l|}{ Comorbidity } \\
\hline Congestive heart failure & $304(4.65)$ & $1224(1.87)$ & $2.56(2.25-2.91)$ \\
\hline Coronary heart disease & $727(11.11)$ & $5674(8.67)$ & $1.32(1.21-1.43)$ \\
\hline Chronic pulmonary disease & 1087(16.62) & 2524(3.86) & $4.97(4.60-5.36)$ \\
\hline Diabetes mellitus & 1274(19.48) & $6234(9.53)$ & $2.30(2.14-2.45)$ \\
\hline End stage renal disease & 182(2.82) & 799(1.22) & $2.32(1.97-2.73)$ \\
\hline Liver cirrhosis & $696(10.64)$ & $3952(6.04)$ & $1.85(1.70-2.02)$ \\
\hline Alcohol abuse & 91(1.39) & $229(0.35)$ & $4.02(2.15-5.13)$ \\
\hline Peptic ulcer disease & 1106(16.90) & $6823(10.43)$ & $1.75(1.63-1.87)$ \\
\hline Reflux esophagitis & 103(1.57) & $664(1.02)$ & $1.56(1.27-1.92)$ \\
\hline Gastrectomy & $23(0.35)$ & 149(0.23) & $1.55(1.01-2.40)$ \\
\hline HIV & $12(0.18)$ & $3(0.00)$ & 40.04(11.3-141.9) \\
\hline Connective tissue disease & 245(3.75) & $1357(2.07)$ & $1.84(1.60-2.11)$ \\
\hline Malignant neoplasm & 704(10.76) & $1906(2.91)$ & $4.02(3.67-4.40)$ \\
\hline Organ transplantation & $21(0.32)$ & $58(0.08)$ & $3.63(2.20-5.99)$ \\
\hline \multicolumn{4}{|l|}{ Medication } \\
\hline PPI & $173(2.64)$ & $723(1.11)$ & $2.43(2.06-2.88)$ \\
\hline $\mathrm{H}_{2} \mathrm{RA}$ & $338(5.16)$ & 1828(2.79) & $1.90(1.68-2.14)$ \\
\hline
\end{tabular}

Abbreviations: TB, Mycobacterium Tuberculosis; Cl, confidence interval; SD, standard deviation; NT, New Taiwan dollars; OR, odds ratio; HIV, human immunodeficiency virus; $\mathrm{PPI}$, proton pump inhibitor; $\mathrm{H}_{2} \mathrm{RA}$, histamine2-receptor antagonist.

Table 3 Association between variable duration of PPI exposure and TB infection/activation

\begin{tabular}{|c|c|c|c|c|}
\hline Exposure & Case (\%) $n=6541$ & Control (\%) $n=65410$ & Crude OR & Adjusted $\mathrm{OR}^{\dagger}$ \\
\hline \multicolumn{5}{|l|}{3 months } \\
\hline Non user & 6368(97.36) & 64687(98.89) & 1 & 1 \\
\hline User & $173(2.64)$ & $723(1.11)$ & $2.43(2.06-2.88)$ & $1.63(1.62-1.63)$ \\
\hline \multicolumn{5}{|l|}{6 months } \\
\hline Non user & 6306(96.41) & $64276(98.27)$ & 1 & 1 \\
\hline User & 235(3.59) & 1134(1.73) & $2.11(1.83-2.44)$ & $1.29(1.29-1.30)$ \\
\hline \multicolumn{5}{|l|}{12 months } \\
\hline Non user & 6221(95.11) & 63575(97.19) & 1 & 1 \\
\hline User & $320(4.89)$ & $1835(2.81)$ & $1.78(1.58-2.01)$ & $0.99(0.99-1.01)$ \\
\hline \multicolumn{5}{|l|}{24 months } \\
\hline Non user & 6103(93.30) & 62519(95.58) & 1 & 1 \\
\hline User & $438(6.70)$ & $2891(4.42)$ & $1.55(1.40-1.72)$ & $0.90(0.89-0.90)$ \\
\hline
\end{tabular}

Abbreviations: OR, odds ratio. †Adjusted for socioeconomic status, congestive heart failure, coronary heart disease, chronic pulmonary disease, diabetes mellitus, end stage renal disease, liver cirrhosis, alcohol abuse, peptic ulcer disease, reflux esophagitis, gastrectomy, HIV, connective tissue disease, malignant neoplasm, organ transplantation. 
Table 4 Association between variable duration of $\mathrm{H}_{2} \mathrm{RA}$ exposure and TB infection/activation

\begin{tabular}{|c|c|c|c|c|}
\hline Exposure & Case $(\%) n=6541$ & Control (\%) $n=65410$ & Crude OR & Adjusted $\mathrm{OR}^{\dagger}$ \\
\hline \multicolumn{5}{|l|}{3 months } \\
\hline Non user & 6203(94.83) & 63582(97.21) & 1 & 1 \\
\hline User & $338(5.17)$ & $1828(2.79)$ & $1.90(1.68-2.14)$ & $1.51(1.50-1.52)$ \\
\hline \multicolumn{5}{|l|}{6 months } \\
\hline Non user & 6073(92.85) & 62528(95.59) & 1 & 1 \\
\hline User & $468(7.15)$ & $2882(4.41)$ & $1.67(1.51-1.85)$ & $1.29(1.28-1.29)$ \\
\hline \multicolumn{5}{|l|}{12 months } \\
\hline Non user & $5847(89.39)$ & $60678(92.77)$ & 1 & 1 \\
\hline User & $694(10.61)$ & $4732(7.23)$ & $1.52(1.40-1.66)$ & 1.15(1.14-1.15) \\
\hline \multicolumn{5}{|l|}{24 months } \\
\hline Non user & $5549(84.83)$ & $57998(88.67)$ & 1 & 1 \\
\hline User & $992(15.17)$ & $7412(11.33)$ & $1.40(1.30-1.50)$ & $1.06(1.05-1.06)$ \\
\hline
\end{tabular}

Abbreviations: OR, odds ratio. †Adjusted for socioeconomic status, congestive heart failure, coronary heart disease, chronic pulmonary disease, diabetes mellitus, end stage renal disease, liver cirrhosis, alcohol abuse, peptic ulcer disease, reflux esophagitis, gastrectomy, HIV, connective tissue disease, malignant neoplasm, organ transplantation.

tuberculosis cases were also under higher risk of TB. $[11,26,27]$. Gastrectomy had also considered an isolated risk factor of Mycobacterium tuberculosis.[14,28] Gastrectomy can cause a poor nutritional status leading to poor immunity, and also leads to a poor nutritional status. $[29,30]$. Long-term PPI therapy has been thought to be associated with micronutrient deficiencies, especially of iron and vitamin B12.[31]. However, the relation between acid suppressive agent and Mycobacterium tuberculosis infection was still unknown.

In the present study, the risk of $\mathrm{TB}$ infection/activation increased when comorbidity existed, compatible with previous findings. After adjusting these confounding factors, acid-suppressive agents associated with an increasing of TB

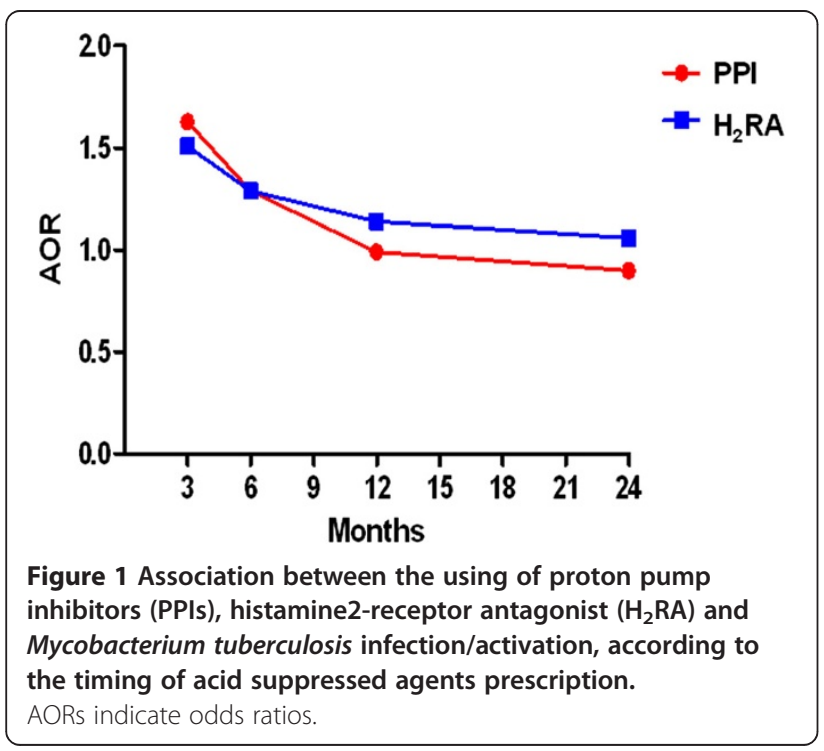

infection/activation. However, the longer duration the medications were prescribed, the weaker correlation it showed.

Two hypothesis was considered to the statistical association of TB and acid-suppressive agent. One was the acidsuppressive agent had influence to the host immune or nutrition status and cause the host sensitive to TB infection/reactivation. It effect declined with time. The other was initial TB presentation (chronic cough) mimicking acid-related disease and caused the prescription of acidsuppressive agent.

Here we defined acid-suppressive agent exposure as the average dosage during the observing period higher than $50 \%$ of DDD. The duration of acid-suppressive agent prescription suggested by NHI guideline was within 4 months after endoscopic diagnosis of peptic ulcers or reflux esophagitis. It seem that acid-suppressive agents were prescribed before TB infection/activation was diagnosed in 3 and 6 months subgroups. Interestingly, in comorbidity analysis, reflux esophagitis was also a risk factor of TB infection/activation. In clinical practice, the acid reflux might be on the list of differential diagnosis for cases who suffered from chronic cough, giving another chance that acid-suppressive agents were taken before anti-TB drug prescription.

The main strength of the present study lies in the use of a true population-based approach, with comprehensive medical records for personal health issue. However, there were some limitations. First, the TB prevalence in the present study was about 49.3 per 100,000 population per year, which was lower than the crude incidence (74.6 per 100,000 population) in Taiwan. [11,32] The reason of underestimated prevalence might come from the definition of TB infection/activation we used, which combined coding system and anti-TB drug prescription record. 
Inactive $\mathrm{TB}$ and cases who had received complete treatment were eliminated from study group. On the contrary, utilizing prescription record could minimize the bias of miscoding. Second, the present study focused on the medical record from NHI research database, which did not include the acid-suppressive agents prescribed from overthe-counter medication. It might underestimate the effect of PPI and $\mathrm{H}_{2} \mathrm{RA}$. Furthermore, it was also difficult to evaluate the drug compliance. Third, some risk factors associated with immunocompromised status, such as poorly controlled diabetes, underweight, malnutrition, were not available, and these factors were possibly influence the TB activation. Fourth, we separated arbitrarily the using of acid suppressive agent in the interval of 3,6,12,24 months and define the exposure as DDD exceeded $50 \%$. This definition would blur the different influence of long-term, short-term, on-off prescription and on-demand prescription. Further prospective study would warrant to this issue.

Undoubtedly, acid-suppressive agents are of great value for treatment of peptic ulcer disease, gastroesophageal reflux disease, or for prophylaxis against nonsteroid antiinflammatory drug-related gastrointestinal complications. Following the increase in PPI use in Taiwan [33], the adverse effect of the drug needs to be further noticed. Similar as the possible role in community-acquired pneumonia, recent prescription of acid-suppressive agent seems to associate the TB infection/activation. Under the consideration of initial TB infection/activation mimic atypical reflux esophagitis, in the society where Mycobacterium tuberculosis was prevalent, evaluation of pulmonary TB was warranted before prescription of acid-suppressive agent.

\section{Competing interest}

The authors declare that they have no competing interest.

\section{Authors' contributions}

WHH, CJL: designed the study and analyzed the results and wrote the manuscript. HMH: designed and supervised the study and directed its implementation, including quality assurance and control. CHK, SSWW, FCK, $C Y L, S K C, Y H C, Y B H, M F H, D C W$ : offered the idea of this study and helped in literature review.

\section{Acknowledgements}

The authors thank the help from the Statistical Analysis Laboratory, Department of Internal Medicine, Kaohsiung Medical University Hospital, and This work was supported by grant from the Department of Health, Executive Yuan, R.O.C. (TAIWAN) (DOH100-TD-C-111-002) and Kaohsiung Medical University Hospital (KMUH100-0I01, KMUH98-8G64, KMUH98-8G63, KMUH98-8R45).

This study is based in part on data from the National Health Insurance Research Database provided by the Bureau of National Health Insurance, Department of Health and managed by National Health Research Institutes (Registered number 98178). The interpretation and conclusions contained herein do not represent those of Bureau of National Health Insurance, Department of Health or National Health Research Institutes.

\section{Author details}

${ }^{1}$ Division of Gastroenterology, Department of Internal Medicine, Kaohsiung Medical University Hospital, Kaohsiung City 807, Taiwan. ${ }^{2}$ Department of Medicine, Faculty of Medicine, College of Medicine, Kaohsiung Medical University, Kaohsiung City 807, Taiwan. ${ }^{3}$ Division of Gastroenterology,
Kaohsiung Chang Gung Memorial Hospital, College of Medicine, Chang Gung University, Kaohsiung City 833, Taiwan. ${ }^{4}$ School of Medicine, College of Medicine, E-Da Hospital, I-Shou University, Kaohsiung City 824, Taiwan. ${ }^{5}$ Division of Infectious Diseases, Department of Internal Medicine, Kaohsiung Medical University Hospital, Kaohsiung City 807, Taiwan. ${ }^{6}$ Graduate Institutes of Clinical Pharmacy, College of Pharmacy, Kaohsiung Medical University, Kaohsiung 807, Taiwan. ${ }^{7}$ Department of Surgery, Kaohsiung Medical University Hospital, Kaohsiung City 807, Taiwan. ${ }^{8}$ Division of Internal Medicine, Kaohsiung Municipal Hsiao-Kang Hospital, Kaohsiung Medical University, Kaohsiung City 812, Taiwan.

Received: 25 March 2013 Accepted: 2 May 2014

Published: 13 May 2014

\section{References}

1. Nardino RJ, Vender RJ, Herbert PN: Overuse of acid-suppressive therapy in hospitalized patients. Am J Gastroentero/ 2000, 95(11):3118-3122.

2. Noguerado Asensio A, Rodriguez Barrientos R, Zelaya Castro P, Sanchez Sempere A, Antuna Blanco F, Lutz Garcia E, Quintana de la Cruz R, Estelles Piera F, Alcazar MS: Use of acid-suppressive medications in hospitalized patients. An Med Interna 2002, 19(11):557-560.

3. Strid $H$, Simren M, Bjornsson ES: Overuse of acid suppressant drugs in patients with chronic renal failure. Nephrol Dial Transplant 2003, 18(3):570-575.

4. Dial S, Delaney JA, Barkun AN, Suissa S: Use of gastric acid-suppressive agents and the risk of community-acquired Clostridium difficileassociated disease. JAMA 2005, 294(23):2989-2995.

5. Garcia Rodriguez LA, Ruigomez A, Panes J: Use of acid-suppressing drugs and the risk of bacterial gastroenteritis. Clin Gastroenterol Hepatol 2007 5(12):1418-1423.

6. Bajaj JS, Zadvornova Y, Heuman DM, Hafeezullah M, Hoffmann RG, Sanyal AJ, Saeian K: Association of proton pump inhibitor therapy with spontaneous bacterial peritonitis in cirrhotic patients with ascites. Am J Gastroenterol 2009, 104(5):1130-1134.

7. Laheij RJ, Sturkenboom MC, Hassing RJ, Dieleman J, Stricker BH, Jansen JB: Risk of community-acquired pneumonia and use of gastric acidsuppressive drugs. JAMA 2004, 292(16):1955-1960.

8. Herzig SJ, Howell MD, Ngo LH, Marcantonio ER: Acid-suppressive medication use and the risk for hospital-acquired pneumonia. JAMA 2009, 301(20):2120-2128.

9. Gulmez SE, Holm A, Frederiksen H, Jensen TG, Pedersen C, Hallas J: Use of proton pump inhibitors and the risk of community-acquired pneumonia: a population-based case-control study. Arch Intern Med 2007, 167(9):950-955.

10. Chiang CY, Kim SJ: Increasing drug resistance of Mycobacterium tuberculosis in a medical center--what about in Taiwan overall? J Formos Med Assoc 2009, 108(1):1-3.

11. Hsueh PR, Liu YC, So J, Liu CY, Yang PC, Luh KT: Mycobacterium tuberculosis in Taiwan. J Infect 2006, 52(2):77-85.

12. WHO global tuberculosis control report: Summary. Cent Eur J Public Health 2010, 18(4):237.

13. Sethi S, Mewara A, Dhatwalia SK, Singh H, Yadav R, Singh K, Gupta D, Wanchu A, Sharma M: Prevalence of multidrug resistance in Mycobacterium tuberculosis isolates from HIV seropositive and seronegative patients with pulmonary tuberculosis in north India. BMC Infect Dis 2013, 13:137.

14. Thorn PA, Brookes VS, Waterhouse JA: Peptic ulcer, partial gastrectomy, and pulmonary tuberculosis. Br Med J 1956, 1(4967):603-608.

15. Steiger Z, Nickel WO, Shannon GJ, Nedwicki EG, Higgins RF: Pulmonary tuberculosis after gastric resection. Am J Surg 1976, 131(6):668-671.

16. Kolappan C, Gopi PG, Subramani R, Narayanan PR: Selected biological and behavioural risk factors associated with pulmonary tuberculosis. Int J Tuberc Lung Dis 2007, 11(9):999-1003.

17. Mori T, Leung CC: Tuberculosis in the global aging population. Infect Dis Clin North Am 2010, 24(3):751-768.

18. Vakil $\mathrm{N}$ : Acid inhibition and infections outside the gastrointestinal tract. Am J Gastroenterol 2009, 104(Suppl 2):S17-20.

19. Sarkar M, Hennessy S, Yang YX: Proton-pump inhibitor use and the risk for community-acquired pneumonia. Ann Intern Med 2008, 149(6):391-398.

20. Myles PR, Hubbard RB, McKeever TM, Pogson Z, Smith CJ, Gibson JE: Risk of community-acquired pneumonia and the use of statins, ace inhibitors and gastric acid suppressants: a population-based case-control study. Pharmacoepidemiol Drug Saf 2009, 18(4):269-275. 
21. Rodriguez LA, Ruigomez A, Wallander MA, Johansson S: Acid-suppressive drugs and community-acquired pneumonia. Epidemiology 2009, 20(6):800-806.

22. Eurich DT, Sadowski CA, Simpson SH, Marrie TJ, Majumdar SR: Recurrent community-acquired pneumonia in patients starting acid-suppressing drugs. Am J Med 2010, 123:47-53.

23. Johnstone J, Nerenberg K, Loeb M: Meta-analysis: proton pump inhibitor use and the risk of community-acquired pneumonia. Aliment Pharmacol Ther 2010, 31(11):1165-1177.

24. Lauderdale TL, Chang FY, Ben RJ, Yin HC, Ni YH, Tsai JW, Cheng SH, Wang JT, Liu YC, Cheng YW, Chen ST, Fung CP, Chuang YC, Cheng HP, Lu DC, Liu CJ, Huang IW, Hung CL, Hsiao CF, Ho M: Etiology of community acquired pneumonia among adult patients requiring hospitalization in Taiwan. Respir Med 2005, 99(9):1079-1086.

25. Apisarnthanarak A, Mundy LM: Etiology of community-acquired pneumonia. Clin Chest Med 2005, 26(1):47-55.

26. Nava-Aguilera E, Andersson N, Harris E, Mitchell S, Hamel C, Shea B, LopezVidal Y, Villegas-Arrizon A, Morales-Perez A: Risk factors associated with recent transmission of tuberculosis: systematic review and meta-analysis. Int J Tuberc Lung Dis 2009, 13(1):17-26.

27. Chin DP, Crane CM, Diul MY, Sun SJ, Agraz R, Taylor S, Desmond E, Wise F: Spread of Mycobacterium tuberculosis in a community implementing recommended elements of tuberculosis control. JAMA 2000, 283(22):2968-2974.

28. Boman K: Tuberculosis occurring after gastrectomy. Acta Chir Scand 1956, 110(6):451-457.

29. Yokoyama T, Sato R, Rikimaru T, Hirai R, Aizawa H: Tuberculosis associated with gastrectomy. J Infect Chemother 2004, 10(5):299-302.

30. Huang SF, Li CP, Feng JY, Chao Y, Su WJ: Increased risk of tuberculosis after gastrectomy and chemotherapy in gastric cancer: a 7-year cohort study. Gastric Cancer 2011, 14(3):257-265.

31. McColl KE: Effect of proton pump inhibitors on vitamins and iron. Am J Gastroenterol 2009, 104(Suppl 2):S5-9.

32. Taiwan tuberculosis control report. 2009, [http://www.cdc.gov.tw/]

33. Chen TJ, Chou LF, Hwang SJ: Trends in prescribing proton pump inhibitors in Taiwan: 1997-2000. Int J Clin Pharmacol Ther 2003, 41(5):207-212.

doi:10.1186/1471-230X-14-91

Cite this article as: Hsu et al:: Acid suppressive agents and risk of

Mycobacterium Tuberculosis: case-control study. BMC Gastroenterology 2014 14:91

\section{Submit your next manuscript to BioMed Central and take full advantage of:}

- Convenient online submission

- Thorough peer review

- No space constraints or color figure charges

- Immediate publication on acceptance

- Inclusion in PubMed, CAS, Scopus and Google Scholar

- Research which is freely available for redistribution 